\title{
Study on Teaching Behaviors Based on Micro-Lesson
}

\author{
Wang Yuanyuan \\ Ideological and Political Department of Xi'an Peihua University, \\ Xi'an, Shaanxi 710125, China \\ e-mail:64789178@qq.com
}

\begin{abstract}
The paper puts forward the "flipped classroom" teaching mode based on micro-lesson, which is aimed at the design and cohesion of the pre class, in class and after class activities in the implementation of the flipped classroom. "Flipped classroom" is the integration of online learning and offline learning. It achieves a new interaction between teaching and learning focusing on time learning theory and time focused discussion. This constitutes a blended teaching model. "Micro-lesson" brought a new atmosphere of teaching. It will further stimulate us to think deeply about the allocation and utilization of technology resources, optimizing the teaching process, coordinating the relationship and maintaining the dynamic balance between teaching and learning. This will improve the teaching ecology.
\end{abstract}

Keywords-Micro-lesson; Flipped Classroom; Teaching behavior

The emergence of micro-lesson is accompanied by the rise of micro learning and massive open online course (MOOCs). It has received more and more attention from the educational circle. The development of micro-lesson meets with the emergence of the global MOOCs. Micro-lesson not only brings us a new way of organizing curriculum teaching resources but also shows us a brand new teaching idea, teaching idea, teaching method and teaching method. It gives birth to the learning environment of micro class as unit. At present, the depth of integration of information technology and teaching is the key and difficult point in teaching reform Chinese, while the use of micro-lesson into the curriculum teaching, is one of the starting points to realize the deep integration of the best goal.

\section{THE ONTOLOGICAL CHARACTERISTICS OF THE} MICRO-LESSON

The definition of micro-lesson is different in the educational field. We believe that micro-lesson is to explain the teaching key points or teaching difficulties or key points analysis. Micro-lesson feature is short, content focus, independent learning. Micro-lesson features determine that does not need big and full, only around a small knowledge point to explain, not too much foreshadowing and rendering, focusing on outstanding. Micro-lesson is an organic combination of teaching resources in the process of classroom teaching aiming at a knowledge point or teaching link. According to the requirements of practical teaching, the teaching video is the main carrier, and the characteristics of micro class ontology are obvious, usually with the following characteristics:

The theme is clear and outstanding. Micro-lesson teaching activities around a certain point of knowledge, such as focus, difficulty, doubt and so on. Micro-lesson can reproduce these contents, so as to replace the teacher lectures. Micro-lesson resources are rich and varied. The role of micro-lesson is not limited to the knowledge points or difficult anatomy. Micro-lesson used to inspire thinking and consolidate learning in the introduction of courses, core knowledge points, curriculum exploration and after-school practice and other links.

Micro-lesson structure is relatively independent. Micro-lesson is a short form of online video. It is an online teaching video for the purpose of learning or teaching applications. The teaching objective of micro-lesson is relatively simple, and the teaching theme is relatively clear. 
It takes teaching video as the carrier. Usually, video Micro-lesson composition see Figure 1. production is controlled in 5 to 10 minutes.

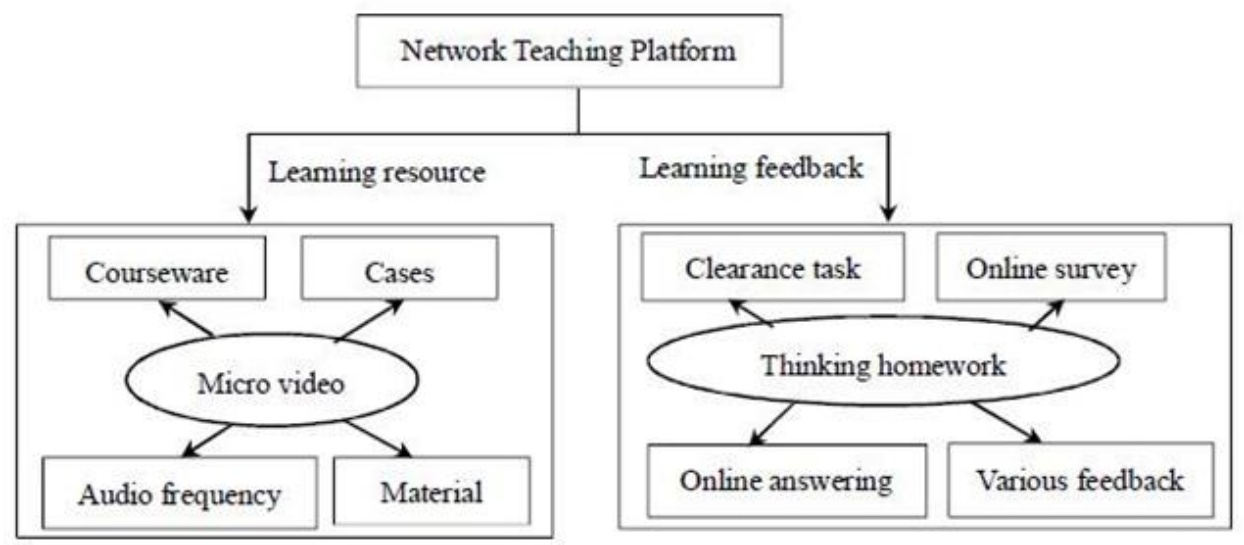

Figure 1. Micro-lesson composition

Network Teaching Platform

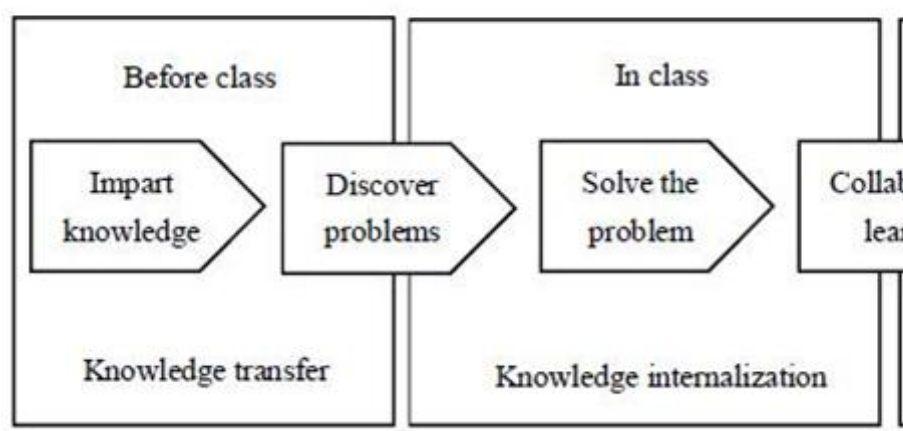

Network Teaching Platform

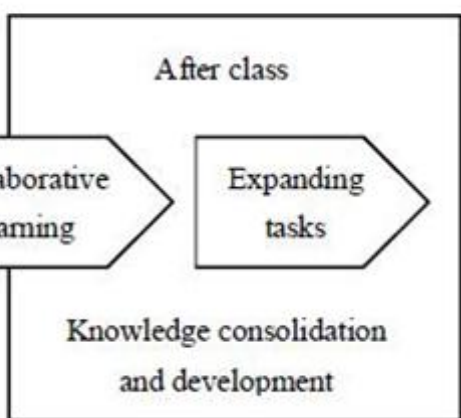

Figure 2. Shematic diagram of teaching design

\section{DESIGN OF FLIPPED CLASSROOM TEACHING MODEL}

\section{BASED ON MICRO-LESSON}

As is known to all, classroom teaching is the process of interaction between teachers and students. Acquiring knowledge is the ultimate goal of classroom teaching. Classroom teaching is not only a simple teaching, students' learning process requires emotional communication between teachers and students, students need to interact with each other, which is the main reason why micro-lesson can't replace classroom teaching. Classroom teaching usually requires the realization of various educational goals, such as knowledge, ability and accomplishment, while micro class usually serves only a single teaching goal. "Flipped classroom" as a teaching design method has become a hot issue for scholars and educators at home and abroad to study and practice. At present, the international research on flipped classroom is more thorough, and has accumulated a certain research foundation. Chinese scholars have also conducted experiments with curriculum. They used questionnaires, interviews, and academic achievement comparison to verify the effectiveness of the specific application model. 
Flipping the classroom is not just a reversal of a simple teaching structure. The flipped classroom teacher is no longer just the instructor of the course content, but also becomes the director and promoter of the learning process. The students change from the audience passively accepted to the active participants in the teaching activities.

The design principles of the flipped classroom include: first, it is beneficial to the construction and internalization of students' knowledge. Second, it is necessary to realize layered teaching. Third, it is helpful for students to master the learning.

The implementation process of "flipped classroom" teaching mode based on micro-lesson see Figure 2.

This model realizes the knowledge transfer, knowledge construction and internalization through the pre class clearance task, typical tasks in class and the extended tasks after class.

1) Pre class preparation stage: video production. There aretwo differences between video in flipped classroom and traditional quality class video. First, flip the micro video in the classroom, the time is about 10 minutes. Therefore, teachers must carefully study the content of teaching, select the core content, and use micro video to explain it. Secondly, in the flipped teaching mode, video teaching is one way teaching, and there is no interactive link. Therefore, we can appropriately add test questions to enhance the interaction.

2) Before class transfer stage: students need to record the problems and achievements in the process of watching videos. At the same time, it is necessary to carry out targeted exercises to consolidate the knowledge and find out the difficulties in learning. Teachers should reasonably design pre class exercises, and control the difficulty and quantity. Students can communicate with each other through communication software, solve problems, and share the results.

3) The inner stage of the classroom: the first part of the classroom is to solve the problems that the teachers collected before the transfer stage. According to the type of problem, inquiry class or discussion class can be organized; the design of classroom activity includes: a) Distribute tasks. Teachers should sum up some valuable questions raised by students through the combination of students' performance. Then, the teacher divides the students according to the teaching task, and selects the group leader. Each group has corresponding learning tasks. The team leader should be responsible for the implementation of the task, and timely feedback to the teacher. At this point, teachers need to exercise the responsibility of "leading the way".

b) Independent exploration. Teachers should cultivate students' independent exploration ability in the flipped classroom. If the team can be more refined, is allocated to each member group, to collect data to solve sub problems respectively, and then the team cooperation, carry out the whole inquiry. In this way, students can form their own knowledge structure system in the process of independent exploration.

c) Teamwork. Collaborative learning allows students to argue through research, argumentation, and dialogue to achieve learning tasks. In the flipped classroom, the teacher needs to capture the students' dynamic, and provide timely guidance to promote the group activities more smoothly. Students realize the construction and internalization of knowledge.

4) Consolidation stage after class: Teachers display excellent learning works on the network teaching platform, according to the students' speech, summary, comments; teachers can also collect teaching content related to expand the learning resources, set up development tasks. Students who have enough spare time can challenge and expand their tasks and realize the consolidation and expansion of students' knowledge.

\section{PRACTICE OF TEACHING MODE COMBINING MICRO-LESSON WITH FLIPPED CLASSROOM}

Design practice plan. The combination of micro-lesson and flipped classroom has been implemented in the course of College Students' Ideological and moral cultivation and legal basis. After the completion of the teaching practice, we use the form of network questionnaire to understand the students recognition of the teaching model. We distribute 589 valid 
answer questionnaires were collected, and the statistical results were as Table 1.

TABLE I. STATISTICAL TABLE OF STUDENTS' SATISFACTION UNDER DIFFERENT TEACHING MODES

\begin{tabular}{|c|c|c|c|}
\hline Studentattitude & Like & Commonly & Do not like \\
\hline $\begin{array}{c}\text { Teacher lecture } \\
\text { Flipped classroom } \\
\text { based on micro-lesson }\end{array}$ & $58.4 \%$ & $38.5 \%$ & $3.1 \%$ \\
\hline Micro class & $18.6 \%$ & $44.5 \%$ & $3.6 \%$ \\
\hline
\end{tabular}

Education is only a single teaching and the educated are passively accepted in the teacher "indoctrination" and "monologue" education oriented teacher teaching. Teachers' ideas can't be educated to educators in a timely manner. The oneness of communication discourse makes education entirely determined by educators. From the statistical table can be seen, students can accept, this is also the students accustomed to the teaching mode. Accepting education as the main body, relying solely on micro-lesson for students' autonomous learning, one-sided emphasis on student oriented "subjectivity" education, from the statistical results, students do not agree. This way eliminates the guiding position of teachers. In the teaching process, based on the micro- lesson flipped classroom design, advocating a "inter subjectivity" education. Inter subjectivity education, training and education in the form of education is the ultimate goal of thinking pattern, which is more in line with the education of "unity", is also accepted by college students.

\section{CONCLUSION}

Most of the previous teaching reforms focus on how teachers carry out effective teaching, focusing on the organization of teaching content, the use of teaching methods and means. Based on the "reform involves the ontological characteristics of micro-lesson teaching design and practice is to "student oriented ", which is" hybrid "and" flip "menu teaching platform for autonomous learning, the students how to learn independently, is convenient, happy to learn and effectively learn problems. This reform is teaching in the face of a new technology initiative, and will further lead us to coordinate the relationship between teaching and learning on the allocation and utilization of technical resources, optimize the teaching process, and in-depth thinking to keep dynamic balance between the teaching of ecological problems. This new teaching mode characterized by "mixed teaching" and "flipped classroom" has changed the traditional way of knowledge dissemination and learning. And the change brought about by this reform is not only the use of new media and new technology, but will lead to profound changes in teaching concepts, teaching methods, teaching mechanisms, personnel training and other fields. Under certain teaching material system and teaching target, it provides us with an effective way to optimize the teaching ecology. So that we can solve the problem of how to effectively allocate teaching resources, we can solve how to effectively use new technology and new carrier in the dissemination of knowledge and theory, and how to effectively realize the dynamic balance between teaching and learning.

\section{ACKNOWLEDGMENT}

This paper is a periodical achievement of the research project of education and teaching reform of Xi'an Peihua University in 2016: Research on the teaching mode of combining micro-lesson with flipped classroom--Take "Ideological and moral cultivation and legal basis" teaching as an example. Item number: PHY1611.

\section{REFERENCE}

[1] Hu Tiesheng. "Micro -lesson": a new trend of the development of regional education information resources [J]. Modern educational technology.2011(10): 61-65.

[2]Ye Mingjun, Li Yongguang. Misunderstandings and Countermeasures of micro class development in Higher Vocational Colleges [J]. Vocational Education Forum. 2017 (26)

[3] Jiao Jianli. Micro-lesson and its application and effect of [J] Information technology education in primary and secondary school. 2013 (4): 13-14.

[4] Liu Rui, Wang Haiyan. Design and practice of "flipped classroom" teaching mode based on micro class [J]. Modern educational technology. 2014 (5). 